\title{
PHYSICS OF AMERICIUM TRANSMUTATION
}

\author{
JANNE WALLENIUS \\ Reactor physics, KTH, AlbaNova University Centre \\ S-10691 Stockholm, Sweden \\ "Corresponding author. E-mail : janne@neutron.kth.se \\ Invited March 23, 2011 \\ Received February 06, 2012 \\ Accepted for Publication February 20, 2012
}

Using fast neutron Generation IV reactors, recycling of americium and curium may become feasible. The detrimental impact of americium on safety parameters has recently been quantified in terms of a power penalty for surviving a given set of transients in sodium fast reactors. In the present paper, a review of the physical reasons for the adverse effect of americium is provided, and different Gen-IV technologies are assessed with respect to their capability of hosting americium in the fuel.

KEYWORDS : Transmutation, Americium, Fast Reactors

\section{INTRODUCTION}

Separation and transmutation of americium and curium, in addition to plutonium, would permit a reduction of high level waste inventories by more than a factor of 100 . The time needed to store the residual waste would consequently shrink dramatically and the capacity of geological repositories would increase significantly. Conducting the recycle of americium and curium in light water reactors would however lead to a very high inventory of neutron emitting ${ }^{252} \mathrm{Cf}$ in fuel cycle facilities, requiring expensive investments in shielding. Hence, these elements should be directed to fast spectrum systems, which would reduce the inventory of ${ }^{252} \mathrm{Cf}$ by more than a factor of 100 [1].

The safety problems appearing when introducing minor actinides into the fuel are however still prevalent in a fast neutron spectrum, and in certain cases they are even more problematic than in a light water reactor. Compared to a "standard" breeder reactor with $(\mathrm{U}, \mathrm{Pu}) \mathrm{O}_{2}$ fuel, the presence of americium will lead to:

(1) A reduction in Doppler feedback

(2) An increase in coolant temperature coefficient

(3) A smaller effective delayed neutron fraction.

The combination of these three phenomena will lead to a reduced safety margin during transients, which must be compensated for by reducing the power density of the fuel. It would be a serious mistake to underestimate the significance of these safety issues. In this paper we will investigate the physics of americium transmutation, explaining in detail the detrimental effects on the aforementioned safety parameters, before discussing innovative Gen-IV solutions permitting to conduct recycling with a minimum cost penalty.

\section{DOPPLER FEEDBACK}

Doppler broadening of capture resonances in even neutron number actinides is the most important safety mechanism in breeder reactors with oxide fuels. The broadening occurs in the laboratory system as a result of increasing amplitude of thermal oscillations of actinide atoms in the crystal lattice of the fuel. The magnitude of the broadening is of the order of the increase in thermal energy, which for $\Delta \mathrm{T}=1000$ Kelvin is $\mathrm{k}_{\mathrm{B}} \Delta \mathrm{T} \approx 0.1 \mathrm{eV}$. Hence, Doppler feedback is more effective for resonances located at lower neutron energies. Consequentially, the magnitude of the Doppler coefficient is smaller in fast reactors than in light water reactors. Figure 1 shows the contribution of neutron captures in ${ }^{238} \mathrm{U}$ resonances as function of energy, when going from cold $(\mathrm{T}=600 \mathrm{~K})$ to hot $\left(\mathrm{T}_{\text {fuel }}=1800 \mathrm{~K}\right)$ state in a sodium cooled core with $\left(\mathrm{U}_{0.8}, \mathrm{Pu}_{0.2}\right) \mathrm{O}_{2}$ fuel. The Doppler feedback deriving from captures taking place above $100 \mathrm{keV}$ is negligible. It is remarkable that captures below $3 \mathrm{keV}$ provide $60 \%$ of the feedback, while constituting only $15 \%$ of the total capture rate!

In order for Doppler feedback to be of significance for core stability, the total magnitude needs to be comparable to typical positive reactivity insertions. As we will see, 


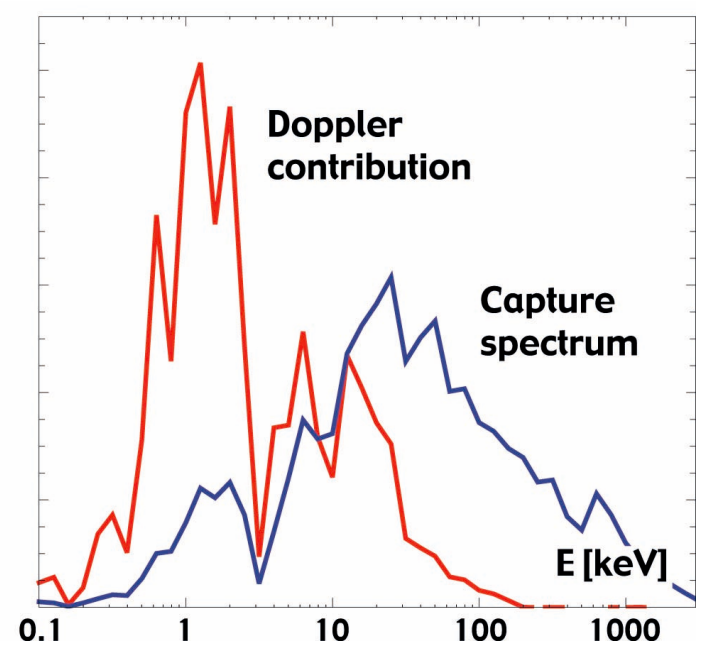

Fig. 1.Relative Contribution of Neutrons in a Given Energy Interval to Total Capture Rate and to the Total Increase in Capture Rate by Doppler Broadening.

Table 1. Doppler Constants for Large Oxide Cores with Varying Content of Uranium and Americium.

\begin{tabular}{c|c}
\hline Fuel & $\mathrm{K}_{\mathrm{D}}[\mathrm{pcm}]$ \\
\hline$\left(\mathrm{U}_{0.8}, \mathrm{Pu}_{0.2}\right) \mathrm{O}_{2}$ & $570 \pm 20$ \\
\hline$\left(\mathrm{U}_{0.7}, \mathrm{Pu}_{0.2}, \mathrm{Am}_{0.1}\right) \mathrm{O}_{2}$ & $230 \pm 20$ \\
\hline$\left(\mathrm{U}_{0.6}, \mathrm{Pu}_{0.2}, \mathrm{Am}_{0.2}\right) \mathrm{O}_{2}$ & $60 \pm 10$ \\
\hline$\left(\mathrm{U}_{0.5}, \mathrm{Pu}_{0.2}, \mathrm{Am}_{0.3}\right) \mathrm{O}_{2}$ & $25 \pm 10$ \\
\hline$\left(\mathrm{Pu}_{0.2}, \mathrm{Am}_{0.3}, \mathrm{Zr}_{0.5}\right) \mathrm{O}_{2}$ & $5 \pm 10$ \\
\hline$\left(\mathrm{Pu}_{0.1}, \mathrm{Zr}_{0.9}\right) \mathrm{O}_{2}$ & $420 \pm 10$ \\
\hline
\end{tabular}

rising coolant temperatures and control rod expulsion may lead to reactivity increases of the order of a few hundred pcm. Loss of coolant, due to boiling or gas bubble formation may introduce more than $1000 \mathrm{pcm}$. In metal fuel cores, axial expansion of the fuel may help in terminating such reactivity transients gracefully, but in reactors with ceramic fuel, Doppler is essential.

Table 1 displays Doppler constants, in units of pcm, for large oxide fuel cores when uranium is substituted with americium. The most striking effect is how the addition of americium to the fuel suppresses Doppler feedback. The more americium we have in the core, the weaker the defence against fast reactivity insertions will become. Note however that fertile plutonium isotopes may yield a strong Doppler feedback in a fuel where neither uranium or americium is present.

The physical reason for the unpleasant behaviour of

\section{Capture cross section [b]}

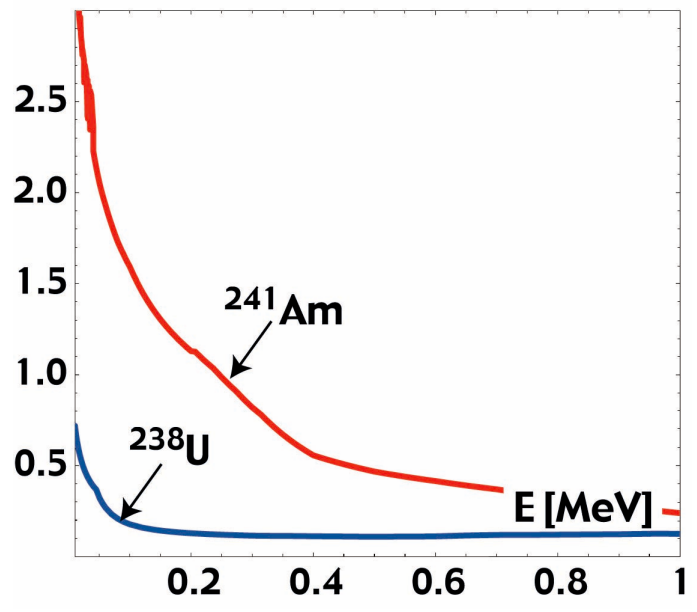

Fig. 2. Capture Cross Sections of ${ }^{241} \mathrm{Am}$ and ${ }^{238} \mathrm{U}$.

Table 2. Capture Distribution in $\left(U_{0.5}, \mathrm{Pu}_{0.2}, \mathrm{Am}_{0.3}\right) \mathrm{O}_{2}$ Fuel.

\begin{tabular}{c|c|c}
\hline Energy & ${ }^{238} \mathrm{U}$ & ${ }^{241} \mathrm{Am}$ \\
\hline $0-1 \mathrm{keV}$ & 0.01 & 0.01 \\
\hline $1-10 \mathrm{keV}$ & 0.11 & 0.11 \\
\hline $10-100 \mathrm{keV}$ & 0.50 & 0.53 \\
\hline $0.1-1 \mathrm{MeV}$ & 0.34 & 0.33 \\
\hline $1-10 \mathrm{MeV}$ & 0.05 & 0.02 \\
\hline
\end{tabular}

americium turns out to be its high cross section for capture of neutrons with energies above $30 \mathrm{keV}$ [2]. Figure 2 compares the cross section of ${ }^{241} \mathrm{Am}$ and ${ }^{238} \mathrm{U}$. The capture cross section of americium is about 10 times larger than that of uranium in this region. Therefore, in an americium bearing fuel, the probability for capture in uranium is reduced much more than what the decrease in uranium concentration would indicate. Substituting the standard fast breeder reactor $(F B R)\left(\mathrm{U}_{0.8}, \mathrm{Pu}_{0.2}\right) \mathrm{O}_{2}$ fuel with $\left(\mathrm{U}_{0.5}, \mathrm{Pu}_{0.2}\right.$, $\left.\mathrm{Am}_{0.3}\right) \mathrm{O}_{2}$, the fraction of neutron captures in ${ }^{238} \mathrm{U}$ drops from $65 \%$ to $18 \%$. In addition, fewer neutrons are able to reach capture resonances below $30 \mathrm{keV}$, which provide the bulk of Doppler feedback.

The distribution of captures over energy in the americium bearing fuel is shown in Table 2. The fraction of captures taking place below $1 \mathrm{keV}$ is reduced by a factor of five, comparing to the fraction for $(\mathrm{U}, \mathrm{Pu}) \mathrm{O}_{2}$ obtained from Figure 2 above. These facts will be very important when selecting an americium transmutation strategy involving fast neutron reactors. 


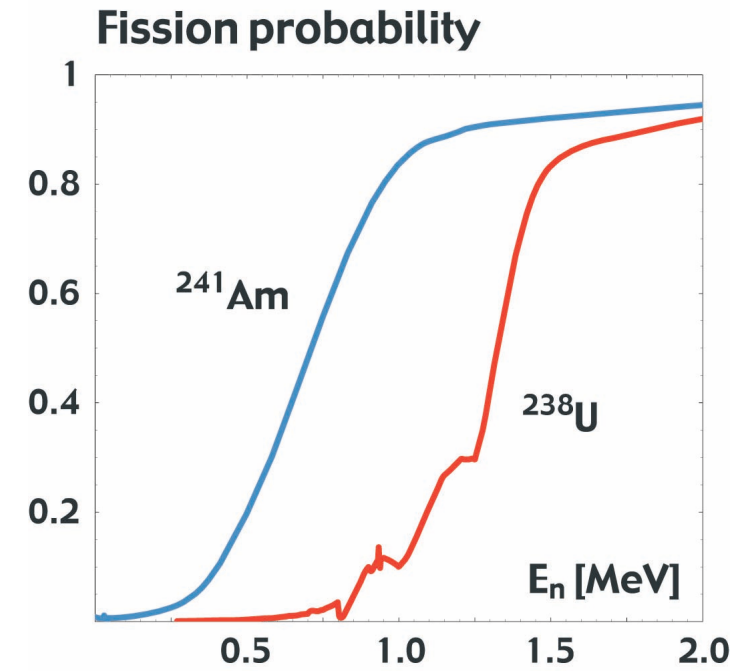

Fig. 3. Fission Probabilities of ${ }^{241} \mathrm{Am}$ and ${ }^{238} \mathrm{U}$.

\section{COOLANT TEMPERATURE COEFFICIENT}

The combination of a fast neutron spectrum with a large concentration of fertile nuclides in the fuel leads to a positive coolant temperature coefficient. Figure 3 illustrates the energy dependence of the fission probability for ${ }^{238} \mathrm{U}$ and ${ }^{241} \mathrm{Am}$. As can be seen, americium is much more sensitive to changes in the magnitude of the neutron flux in the energy region between 0.2 and $0.8 \mathrm{MeV}$. Since fission of higher actinides produces more neutrons than fission of uranium and plutonium, a hardening of the spectrum will increase the average value of $v$. The combination of these two effects lead to a higher coolant temperature coefficient in reactors dedicated to transmutation than in classical breeder reactors.

The integral (core averaged) temperature coefficient is a balance between the positive contribution from hardening of the neutron spectrum and negative contributions from increase in leakage and reduction of capture in the coolant. The leakage effect is particularly important for cores with large surface to volume ratio. The relative fraction of plutonium (or fissile to fertile ratio) in the fuel also plays an important role. The fission probability is close to unity for fissile nuclides in a fast spectrum. A change in spectrum therefore will not have a significant impact on reactivity. Since small cores usually require a higher plutonium fraction to achieve criticality, they will exhibit a lower, and possibly even negative coolant temperature coefficient. Other ways to increase the leakage component is to reduce the height to diameter ratio $(\mathrm{H} / \mathrm{D})$, or to introduce heterogeneities in the core design [3].

Table 3 compares sodium temperature coefficients calculated at $\mathrm{T}=690 \mathrm{~K}$ for different oxide fuels in a medium sized core with pin pitch to diameter ratio (P/D) equal to
Table 3. Sodium Temperature Coefficient for a 1500 MWth core, in Units of $\mathrm{pcm} / \mathrm{K}$.

\begin{tabular}{c|c}
\hline Fuel & $\alpha_{\mathrm{Na}}$ \\
\hline$\left(\mathrm{U}_{0.8}, \mathrm{Pu}_{0.2}\right) \mathrm{O}_{2}$ & +0.17 \\
\hline$\left(\mathrm{U}_{0.7}, \mathrm{Pu}_{0.2}, \mathrm{Am}_{0.1}\right) \mathrm{O}_{2}$ & +0.34 \\
\hline$\left(\mathrm{U}_{0.6}, \mathrm{Pu}_{0.2}, \mathrm{Am}_{0.2}\right) \mathrm{O}_{2}$ & +0.47 \\
\hline$\left(\mathrm{U}_{0.5}, \mathrm{Pu}_{0.2}, \mathrm{Am}_{0.3}\right) \mathrm{O}_{2}$ & +0.58 \\
\hline$\left(\mathrm{Pu}_{0.2}, \mathrm{Am}_{0.3}, \mathrm{Zr}_{0.5}\right) \mathrm{O}_{2}$ & +0.53 \\
\hline$\left(\mathrm{Pu}_{0.1}, \mathrm{Zr}_{0.9}\right) \mathrm{O}_{2}$ & -0.35 \\
\hline
\end{tabular}

1.24 , a steel radial reflector and a power of $1500 \mathrm{MW}_{\text {th. }}$. The substitution of uranium with americium leads to an increase in the sodium temperature coefficient which is significant already for a few percent Am in the fuel. The pure plutonium fuel, on the other hand, comes with a negative coolant temperature coefficient $\left(\alpha_{\mathrm{Na}}\right)$, even though the core size is identical.

We may compare the magnitude of the core averaged temperature coefficient with the Doppler feedback, by assuming an average operating temperature of the fuel. For oxide fuels, 1500 Kelvin may be considered as a typical value, giving $\alpha_{D}=-0.2 \mathrm{pcm} / \mathrm{K}$ in the case of a fuel containing $10 \%$ americium (see Table 1). A small increase in coolant temperature would thus lead to a prompt increase in reactivity for such a fuel, even after Doppler feedback is taken into account.

\section{EFFECTIVE DELAYED NEUTRON FRACTION}

Delayed neutrons are emitted by certain decaying fission products up to one minute after the original fission. The most important precursors for delayed neutrons are bromine, rubidium and iodine. The yield of these elements is different for each actinide. In particular the average mass of the light fission product varies with the mass of the mother nuclide, since it to a lesser extent is pinned by the presence of doubly magic nuclei. One therefore finds that the yield of bromine isotopes falls by a factor of five when going from ${ }^{235} \mathrm{U}$ to ${ }^{245} \mathrm{Cm}$, as illustrated in Figure 4.

The relative fraction of delayed neutrons produced by a fission is denoted $\beta$. In general, $\beta$ decreases with atomic number, but increases with number of neutrons. The highest $\beta$ value is thus found for ${ }^{232} \mathrm{Th}$, and the lowest for ${ }^{241} \mathrm{Am}$ and ${ }^{244} \mathrm{Cm}$. Table 4 compares $\beta$ for the two latter nuclides with those of ${ }^{238} \mathrm{U}$ and ${ }^{239} \mathrm{Pu}$, explaining why the average $\beta$ value is reduced for uranium free fuels.

Delayed neutrons are born with a neutron spectrum that differs qualitatively from that of the prompt fission 


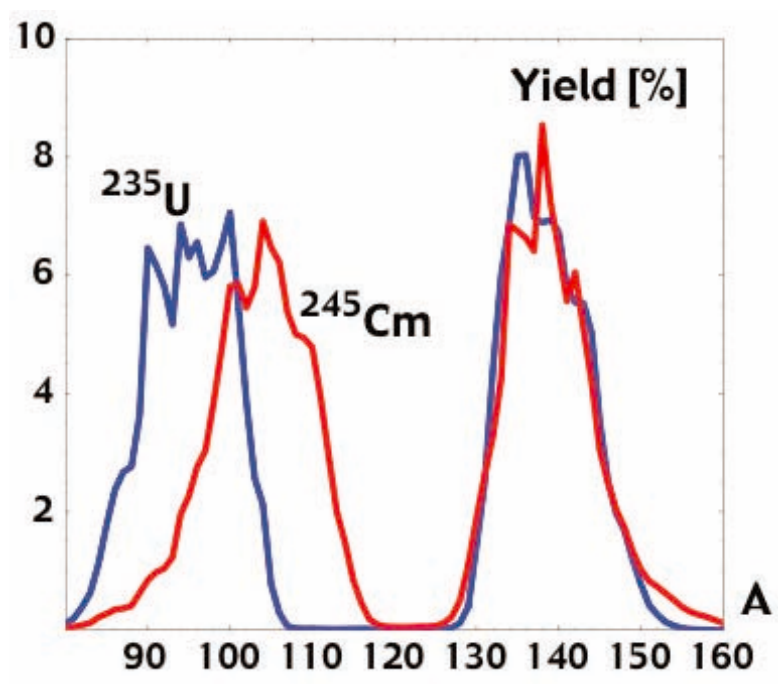

Fig. 4. Fission Product mass Distribution of ${ }^{235} \mathrm{U}$ and ${ }^{245} \mathrm{Cm}$.

Table 4. Fission Neutron yield and Delayed Neutron Fraction for 1.0 MeV Neutrons.

\begin{tabular}{c|c|c}
\hline Nuclide & $v_{\text {tot }}$ & $v_{\mathrm{d}} / v_{\text {tot }}$ \\
\hline${ }^{238} \mathrm{U}$ & 2.53 & $1.89 \%$ \\
\hline${ }^{239} \mathrm{Pu}$ & 3.02 & $0.22 \%$ \\
\hline${ }^{241} \mathrm{Am}$ & 3.37 & $0.13 \%$ \\
\hline${ }^{244} \mathrm{Cm}$ & 3.42 & $0.13 \%$ \\
\hline
\end{tabular}

neutrons, as illustrated in Figure 5. For instance, the median delayed neutron energy is about $0.5 \mathrm{MeV}$, which may be compared to the median prompt neutron energy of $1.6 \mathrm{MeV}$. An important consequence of this fact is that delayed neutrons do not induce fission with the same probability as do prompt neutrons. In a fast neutron spectrum, delayed neutrons are less likely to fission even neutron number nuclides. When calculating the growth rate of the neutron population one should therefore use the effective delayed neutron fraction $\beta_{\mathrm{eff}}$, defined as the fraction of fission inducing neutrons that were born as delayed neutrons. In a fast spectrum system we have $\beta_{\mathrm{eff}}<\beta$. For standard (U, $\mathrm{Pu}) \mathrm{O}_{2}$ fuels, one typically has $\beta_{\mathrm{eff}} \approx 0.85 \beta$.

Considering transmutation, americium once again turns out to be the villain. Its very high capture cross section at energies below $0.5 \mathrm{MeV}$ reduces the efficiency of the delayed neutrons in americium bearing fuels even further. Table 5 displays values for $\beta$ and $\beta_{\text {eff }}$ in the simplified core model previously used to calculate Doppler constants. With $30 \%$ Am in the fuel, $\beta_{\text {ef }} \approx 0.61 \beta$, leading to values

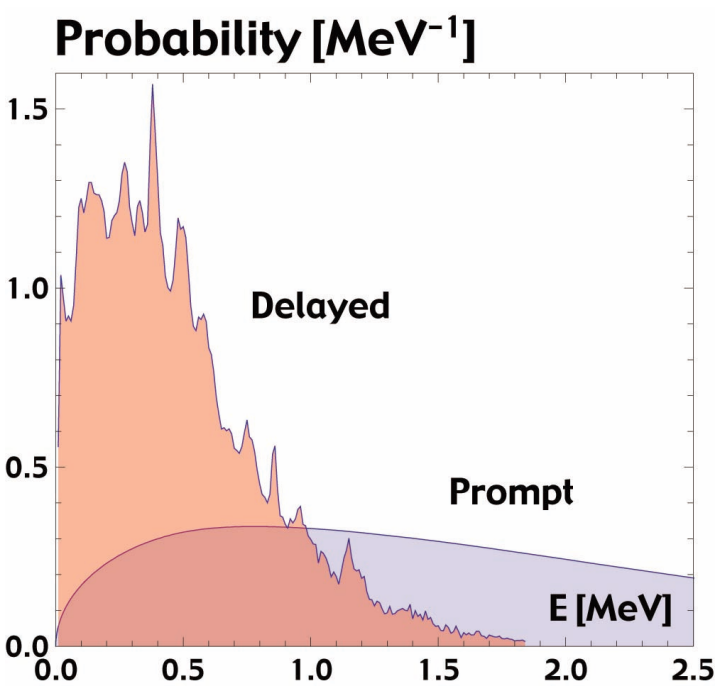

Fig. 5. Spectrum of Delayed and Prompt Neutrons from Fission of ${ }^{239} \mathrm{Pu}$.

Table 5. Delayed and Effective Delayed Neutron Fraction (in Units of pcm) for Large Oxide Cores with Varying Americium Content.

\begin{tabular}{c|c}
\hline Fuel & $\beta_{\text {eff }} / \beta$ \\
\hline$\left(\mathrm{U}_{0.8}, \mathrm{Pu}_{0.2}\right) \mathrm{O}_{2}$ & $390 / 460$ \\
\hline$\left(\mathrm{U}_{0.6}, \mathrm{Pu}_{0.2}, \mathrm{Am}_{0.2}\right) \mathrm{O}_{2}$ & $270 / 390$ \\
\hline$\left(\mathrm{U}_{0.5}, \mathrm{Pu}_{0.2}, \mathrm{Am}_{0.3}\right) \mathrm{O}_{2}$ & $220 / 350$ \\
\hline$\left(\mathrm{Pu}_{0.2}, \mathrm{Am}_{0.3}, \mathrm{Zr}_{0.5}\right) \mathrm{O}_{2}$ & $160 / 260$ \\
\hline$\left(\mathrm{Pu}_{0.1}, \mathrm{Zr}_{0.9}\right) \mathrm{O}_{2}$ & $290 / 310$ \\
\hline
\end{tabular}

of $\beta_{\text {eff }}$ smaller than 230 pcm even when uranium is present. The sensitivity to reactivity perturbations thus increases. As we have seen, the magnitude of such perturbations also increases with americium in the basket.

\section{IMPACT ON TRANSIENT BEHAVIOUR}

Until recently, no proper study on the transient performance of fast reactors had been conducted as function of americium concentration in the fuel. A few studies have stated that a given fixed concentration of about $2 \%$ is acceptable in large sodium cooled fast reactors (SFRs) with oxide fuel $[4,5]$, albeit without a proper transient analysis to back up the claim.

Wallenius and Zhang therefore developed a consistent methodology to investigate the influence of americium on the behaviour of liquid metal cooled reactors during a set of representative design basis conditions, such as 


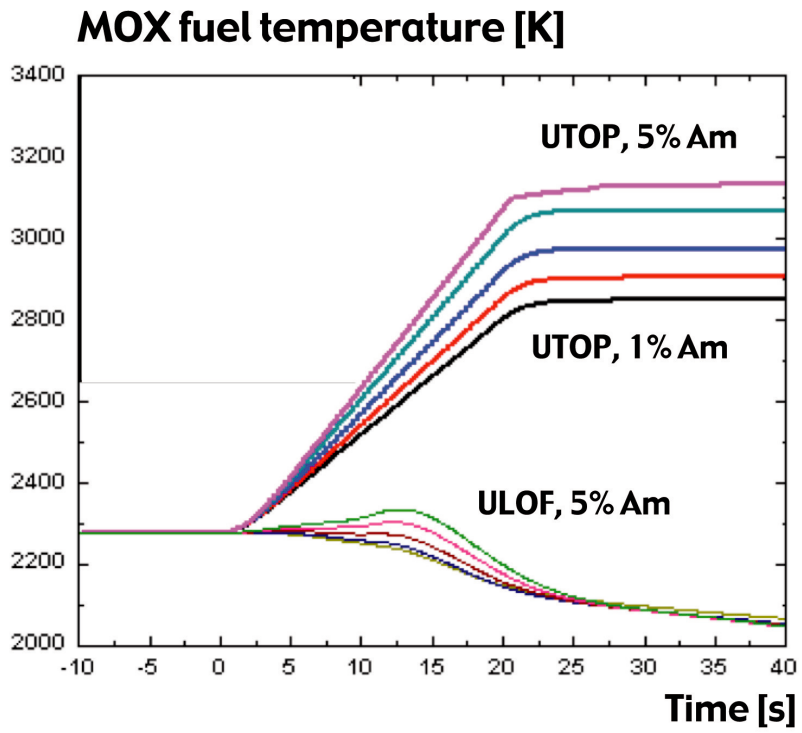

Fig. 6. Fuel Temperature During a UTOP, for Americium Content Ranging from 1 to 5\% in the MOX Fuel of a Sodium Fast Reactor.

unprotected transient overpower (UTOP) and unprotected loss of flow (ULOF) [6]. The approach consists of designing a reference core with a uranium-plutonium fuel to have a certain temperature margin to failure during the above set of transients. Then, by gradually increasing the americium fraction, the reduction in power density required to maintain the same margin to failure becomes a measure of the penalty resulting from the presence of americium in the fuel.

Figure 6 shows how the maximum temperature in the MOX fuel of a medium sized sodium fast reactor increases as function of americium content, following a UTOP resulting from a reactivity insertion of one dollar with a rate of $0.05 \$$ per second [6]. For this accident, Doppler broadening is the most important negative feedback mechanism. As the Doppler constant is reduced, a higher asymptotic temperature is required to balance the positive reactivity insertion with negative temperature feedback from the fuel, the temperature of which increases with 50 $\mathrm{K}$ for every additional percent americium. In order to maintain the same margin to melting, the nominal power density of the SFR would have to be reduced by six percent per percent americium.

The equilibrium fraction of americium in the fuel in a typical fast spectrum system is $1 \%$. Hence, in order for the reactor to function as an americium burner, the fuel has to contain more than $1 \% \mathrm{Am}$ at beginning of life (BOL). With $20 \%$ plutonium in the fuel, the burning rate of Am is roughly $1.7 \mathrm{~kg}$ per TWh for every additional percent of americium. In order to achieve a burning rate of $7 \mathrm{~kg} \mathrm{Am}$ per TWh (the production rate of higher actinides in light water reactors), it is thus required to load the fuel with $5 \%$ americium, leading to a power penalty of $25 \%$. Since capital costs remain the same, this power penalty will lead to an increase in the cost for SFR electricity of a similar magnitude.

The relatively large cost penalty for conducting americium transmutation in MOX fuelled SFRs is hence an incentive to investigate alternative design choices.

\section{HETEROGENEOUS RECYCLING IN MOX CORES.}

The softer spectrum and the higher importance of leakage in the periphery of the core permit larger concentrations of americium in this region. Placing separated americium only in dedicated assemblies located at the periphery of a standard $(\mathrm{U}, \mathrm{Pu}) \mathrm{O}_{2}$ core, therefore allowing improved safety perameters and increased burning rates for $\mathrm{Am}$ and $\mathrm{Cm}$ [7]. A core averaged net burning rate of 6-7 $\mathrm{kg}$ higher actinides per $\mathrm{TWh}_{\mathrm{e}}$ is possible to achieve in such configurations, meaning that the higher actinide inventory may be stabilised with about $50 \%$ fast reactors in the power park.

In the most straightforward option, americium is replacing depleted uranium in the dedicated assemblies. Concentrating the americium in $40 \%$ of the assemblies of the core leads to a decrease in the sodium void worth of five percent and an increase of the Doppler constant of 13 percent [8].

In the so called "target" concept, the uranium is substituted with an inert matrix, such as $\mathrm{MgO}$. In this case, the small fission probability of americium leads to a large variation in the power density in target assemblies, 
as plutonium is built up through the decay of ${ }^{242} \mathrm{Cm}$. At BOL, the targets thus contribute negatively to the neutron balance of the core.

One may also consider the possibility of moderating the fast neutrons leaking out of the standard core, in order to decrease the radiation damage dose to the cladding tubes in the target assemblies. Calculations indicate that a burnup of $90 \%$ would be possible to achieve in an assembly where $\mathrm{AmO}_{2}-\mathrm{MgO}$ target pins are mixed with $\mathrm{ZrH}$ moderator pins [9]. This result is however dependent on the assumption that the clad may withstand a dose of $200 \mathrm{dpa}$. The threshold for swelling of cladding tube steels is dependent on dose rate, and a material surviving up to $200 \mathrm{dpa}$ in a high flux fast neutron spectrum does not necessarily do so in a moderated spectrum with lower dose rate.

With heterogeneous recycling of higher actinides in MOX fuelled SFRs, one thus maximises the transmutation capability in reactor concepts proven on industrial scale. Fuel cycle facilities for target fabrication and reprocessing could be designed for smaller mass flows, which is a clear benefit when dealing with highly active elements. From a technical viewpoint the large production of helium in the target pins (mainly being a result of the decay of ${ }^{242} \mathrm{Cm}$ ) will require tall gas plenums to be introduced [10], with consequences for the core design in general.

\section{METAL ALLOY FUEL}

In the Unites States, metal alloy fuel has been developed as an alternative fuel for fast breeder/burner reactors within the Integral Fast Reactor (IFR) programme [11]. By mixing uranium and plutonium with zirconium, a radiation resistant alloy with improved thermal properties is obtained. The high swelling rate of metallic fuels can be accommodated by introducing a large gap between the fuel slug and the clad, which then is filled with liquid sodium to keep fuel temperatures below the melting point of the alloy. Starting with a smear density of $75 \%$, the metal fuel initially swells rapidly until fission gas release occurs. The fuel then becomes sponge-like, which means that fuel-clad mechanical interaction is less severe. Burnups of about $20 \%$ have been achieved in test irradiations.

An important advantage of metallic fuels in the context of transmutation is the high thermal expansion coefficient of the actinide based alloy. In standard fast reactor configurations, the axial expansion of the fuel slug, which acts on a time scale of milli-seconds, compensates for the degraded Doppler feedback of the metallic fuel. This is particularly important for the performance under UTOP accidents. Since axial expansion is not significantly affected by the introduction of americium in the fuel, the power penalty of metallic fuelled cores is only $3 \%$ per percent americium in the fuel [12]. This is about half the penalty pertaining to the MOX fuelled SFR. Moreover, the harder spectrum and the higher actinide density of the metallic fuel permit a smaller fraction of plutonium in the fuel to achieve a conversion ratio equal to unity. The equilibrium concentration of $\mathrm{Pu}$ is about $12 \%$, which may be compared to $16 \%$ for MOX fuelled SFRs. Hence, the production rate of americium is smaller in the metal core, leading to a better net consumption of higher actinides.

The fraction of power required to be produced in fast neutron reactors, in order to stabilise higher actinide inventories, thus may be reduced.

Manufacturing methods for americium bearing metal fuels are still not suitable for large-scale production. An additional drawback is the need for sodium bonded fuel pins. Consequently, aqueous methods cannot be used for reprocessing of this fuel type. Pyroprocesses, where the fuel is dissolved in a molten salt, could be applied, but have so far not enabled to recover more than $99 \%$ of the actinide mass when operated on a pilot scale. Losses of the order of one percent in every reprocessing cycle are clearly incompatible with the objective of reducing radiotoxic inventories by more than a factor of 100 .

\section{NITRIDE FUEL}

Nitride fuels have the advantage of combining a high melting temperature with a high thermal conductivity. The margin to fuel failure therefore is larger than for oxide and metallic fuels. In simulation of unprotected transients, one therefore finds that the fuel will not constitute the limiting factor. Rather, it will be the cladding which fails first. As nitride fuels yield a harder spectrum than oxide fuels, the Doppler constant will be smaller than for oxides. Thanks to the lower operational temperature of the fuel, the Doppler coefficient in nitride and oxide cores will still be of similar magnitude, leading to similar responses to unprotected loss of flow accidents. In comparison to metallic alloy fuels, the axial expansion feedback will be somewhat smaller. Hence, a sodium cooled reactor with nitride fuel is slightly more sensitive to ULOF accidents than its metal fuel counterpart.

\section{LEAD COOLANT}

Lead has a melting temperature of $603 \mathrm{~K}$ and is a potential coolant for fast neutron reactors. Besides being inert with respect to water it has the advantages of a high boiling temperature $(2024 \mathrm{~K})$ and in absolute numbers, large thermal expansion. These features make coolant voiding less likely and permits a significant amount of heat removal by natural circulation[13]. Lead cooling is therefore of special interest in the context of minor actinide transmutation, where void worths and decay heating rates are high. In particular it will be easier to design the primary system to survive unprotected loss of flow accidents.

A major problem related to application of lead and 
lead alloys is corrosion of clad and structural materials in the reactor. Eutectic lead-bismuth, which has a melting temperature of $398 \mathrm{~K}$, has already been used in Russian submarine reactors in the early sixties. However, blockage of fuel assemblies due to accumulation of corrosion products caused a core melt in the first operational submarine. Methods for controlling the oxygen content in the molten metal were subsequently developed which allowed for successful operation of eight so called "alpha"-class submarines for a total of 80 reactor years. Bismuth is however a relatively scarce metal. Further, neutron capture during irradiation leads to the production of the highly radio-toxic nuclide ${ }^{210} \mathrm{Po}$. For commercial application, it is therefore considered that pure lead should be used.

Oxygen control technology, novel steel compositions and surface alloying techniques have since been developed that appear to proved adequate corrosion protection over extended exposure times in temperature ranges typical for the operation of lead fast reactors, that is $670-820 \mathrm{~K}$.

A power reactor design based on lead cooling and nitride fuel was developed in Russia under the acronym BREST [14]. This particular combination of fuel and coolant makes the design highly resistant to both UTOP and ULOF accidents, which will permit loading of a higher fraction of minor actinides and hence maximise transmutation rates.

The ELSY design of a lead-cooled fast reactor with mixed oxide fuel made by a European collaboration [15] has an exceptionally good performance under loss of flow accidents. The margin to melt for the fuel is however no better than for the corresponding SFRs, resulting in a similar power penalty when introducing americium into the core [16].

\section{SUMMARY AND CONCLUSIONS}

Plutonium is easily recycled in fast reactors, which may act as either Pu breeders or burners. Multirecycling of americium and curium in a fast neutron system reduces the production of californium by two orders of magnitude, as compared to recycling in a PWR. Fast reactors hence are the preferred choice for higher actinide management.

Introduction of americium into the fuel however reduces Doppler feedback, increases the coolant temperature coefficient and reduces the effective delayed neutron fraction.

In order to maintain a sufficient margin to fuel and clad failure during unprotected transients, the linear power density of the core must be reduced as the americium concentration increases. For homogeneous recycling in SFRs with MOX cores, the reduction of linear power density has been estimated to six percent per percent americium.

Development of innovative fuels and/or coolants could reduce this power penalty down to a value of three percent per percent americium. This would enable to stabilise the minor actinide inventory in a nuclear power park where $25 \%$ of all energy is produced in Generation-IV fast neutron reactors.

\section{ACKNOWLEDGEMENTS}

Financial support from SKB (The Swedish Nuclear Fuel and Waste Management Company) and KNS (Korean Nuclear Society) is gratefully acknowledged.

\section{REFERENCES}

[ 1 ] M. Salvatores et al., "Intercomparison of systems for TRU recycling at equilibrium," Proc. Int. Conf. Nuclear Energy Systems for Future Generation and Global Sustainability (GLOBAL05), Tsukuba, Japan, 2005, AESJ (2005).

[2] J. Wallenius and M. Eriksson, "Neutronic design of minor actinide burning accelerator-driven systems with ceramic fuel," Nucl. Technol., 152, 367 (2005).

[ 3 ] H.S. Khalil and R.N. Hill, "Evaluation of liquid metal reactor design options for reduction of sodium void worth," Nucl. Sci. Eng., 109, 221 (1991).

[4] J. Tommasi et al., "Long-lived waste transmutation in reactors," Nucl. Technol., 111, 133 (1995).

[5] T. Wakabayashi, S. Ohki and T. Ikegami, "Feasibility studies of an optimised reactor core for MA and FP transmutation," Proc. Int. Conf. Evaluation of Emerging Nuclear Fuel Cycle Systems (GLOBAL95), Versailles, France, 1995, ANS (1995).

[6] Y. Zhang, J. Wallenius and A. Fokau, "Transmutation of americium in a medium sized sodium cooled fast reactor design," Ann. Nucl. Energy, 37, 629 (2010).

[ 7 ] D. Verrier et al., "Heterogeneous recycling of americium in (Am, $\mathrm{Pu}) \mathrm{O}_{2}$ target subassemblies in a fast reactor core," Proc. Int. Conf. Evaluation of Emerging Nuclear Fuel Cycle Systems (GLOBAL95), Versailles, France, 1995, ANS (1995).

[8 ] P. Fernandez, "Transmutation of minor actinides in a sodium cooled fast reactor," MSc thesis TRITA-FYS 2009:38, KTH, Sweden (2009).

[9 ] C. De Saint Jean et al., "Americium and curium heterogeneous transmutation in moderated S/A in the framework of CNE scenarios studies," Proc. Int. Conf. Back-End of the Fuel Cycle: From Research to Solutions (GLOBAL01), Paris, France, 2001, ANS (2001).

[10] H. Beaumont et al., "Heterogeneous minor actinide recycling in the CAPRA high burnup-core with target subassemblies," Proc. Int. Conf. Future Nuclear Systems (GLOBAL99), Jackson Hole, Wyoming, 1999, ANS (1999).

[11] D.C. Wade and R.N. Hill, "The design rationale of the IFR," Prog. Nucl. Energy, 31, 13 (1997).

[12] Y. Zhang and J. Wallenius, "Upper limits to americium concentration in large sized sodium fast reactors loaded with metallic fuel," submitted to Nucl. Sci. Eng., 2011.

[13] Ser Gi Hong, Ehud Greenspan, Yeong Il Kim, “The encapsulated nuclear heat source (ENHS) reactor core design," Nucl. Technol., 149, 22 (2005).

[14] E.O. Adamov et al., "The Next Generation of Fast Reactors," Nucl. Eng. Des., 173, 143 (1997).

[15] L. Cinotti et al., "The potential of the LFR and the ELSY project," Proc. Int. Congress on Advances in Nuclear 
Power Plants (ICAPP 2007), Nice, France, May 13-18, 2007 (2007).

[16] M. Tesinsky, Y. Zhang and J. Wallenius, "The impact of americium on the ULOF and UTOP transients of the European Lead Cooled System ELSY," submitted to Ann. Nucl. Energy, 2011. 